\title{
BMJ Open Fertility rates and the postponement of first births: a descriptive study with Finnish population data
}

\author{
Zahra Roustaei, ${ }^{1}$ Sari Räisänen, ${ }^{2}$ Mika Gissler, ${ }^{3,4}$ Seppo Heinonen ${ }^{5}$
}

To cite: Roustaei Z, Räisänen S, Gissler M, et al. Fertility rates and the postponement of first births: a descriptive study with Finnish population data. BMJ Open 2019;9:e026336. doi:10.1136/ bmjopen-2018-026336

- Prepublication history and additional material for this paper are available online. To view these files, please visit the journal online (http://dx.doi org/10.1136/bmjopen-2018026336).

Received 27 August 2018 Revised 11 0ctober 2018 Accepted 7 November 2018

Check for updates

(C) Author(s) (or their employer(s)) 2019. Re-use permitted under CC BY-NC. No commercial re-use. See rights and permissions. Published by BMJ.

${ }^{1}$ Department of Health Sciences, University of Helsinki, Helsinki,

Finland

${ }^{2}$ School of Health Care and Social Services, Tampere University of Applied Sciences, Tampere, Finland

${ }^{3}$ Information Services

Department, THL National

Institute for Health and Welfare, Helsinki, Finland

${ }^{4}$ Department of Neurobiology Care Sciences and Society, Division of Family Medicine and Primary Care, Karolinska Institutet, Stockholm, Sweden ${ }^{5}$ Department of Obstetrics and Gynecology, University of Helsinki and Helsinki University Hospital, Helsinki, Finland

Correspondence to

Zahra Roustaei;

zahra.roustaei@helsinki.fi

\section{ABSTRACT}

Objectives We described the trend of fertility rates, agespecific fertility rates and associated factors in Finland over a 30-year period.

Design A descriptive population-based register study. Setting Fertility data, including age at first birth, childlessness and educational levels were gathered from the Finnish Medical Birth Register and Statistics Finland. Participants All 1792792 live births from 1987 to 2016 in Finland.

Main outcome measures Completed fertility rate, total fertility rate and age-specific fertility rate.

Results The total fertility rate of Finnish women fluctuated substantially from 1987 to 2016 . Since 2010 , the total fertility rate has gradually declined and reached the lowest during the study period in 2016: 1.57 children per woman. The mean maternal age at first birth rose by 2.5 years from 26.5 years in 1987 to 29 years in 2016. The proportion of childless women at the age of 50 years increased from $13.6 \%$ in 1989 to $19.6 \%$ in 2016. By considering the impact of postponement and childlessness, the effect on total fertility rates was between -0.01 and -0.12 points. Since 1987 , the distribution of birth has declined for women under the age of 29 and increased for women aged 30 or more. However start of childbearing after the age of 30 years was related to the completed fertility rate of less than two children per woman. The difference in completed fertility rate across educational groups was small.

Conclusions Postponement of first births was followed by decline in completed fertility rate. Increasing rate of childlessness, besides the mean age at first birth, was an important determinant for declined fertility rates, but the relation between women's educational levels and the completed fertility rate was relatively weak.

\section{INTRODUCTION}

Women are postponing childbearing to a later age, mainly because of enrolling in tertiary education, focusing on employment, having housing and economic uncertainty, engaging in premarital cohabitation and delaying marriage at later ages. ${ }^{12}$ In addition, men play an important role in delaying parenthood because of having inadequate knowledge about reproductive lifespan and postponing forming partnerships and parenting with

\section{Strengths and limitations of this study}

The current study drawn from well-established population registers, including information of 1792792 live births.

- The data in Finnish population registers have high coverage and validity.

- The focus of study was on the total fertility rate by time and maternal age, without focus on specific exposure effect.

- In this study, we were unable to distinguish voluntary from involuntary childlessness.

women. ${ }^{3}$ These complex trends, which affect the decision of having a child, may differ across socioeconomic groups. ${ }^{45}$

It has been documented that advanced maternal and paternal age affects negatively fecundability, and the physiological ability of couples to conceive. ${ }^{6-10}$ The strength of the negative association between female age and fertility has found to be even stronger in women who have never conceived, since they may suffer from primary infertility. ${ }^{11}$

At the population level, fertility rates appear to reflect demographic trends, social changes and family policies which may vary from country to country. ${ }^{4}$ For example, in France, the effect of postponing pregnancy on the total fertility rate has been shown to be marginal. ${ }^{12}$ In Finland, the total fertility rate has declined by almost one-third over a century (figure 1A). The total fertility rate declined in the beginning of the 20th century with the spread of parity-specific fertility control through Finland. After World War II, declines in the mean age at marriage reduced the mean maternal age at first birth and contributed to the baby boom. After 1950, the total fertility rate of Finnish women declined and went below the replacement level of 2.1 children per woman in $1969 .{ }^{13}$

Finland has witnessed the lowest recorded fertility rate and the highest ever mean maternal age at first birth during the year 
A

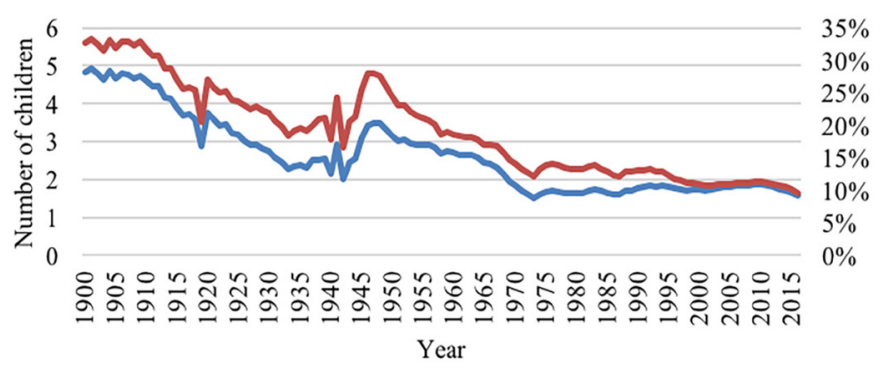

Total fertility rate $\longrightarrow$ Crude birth rate

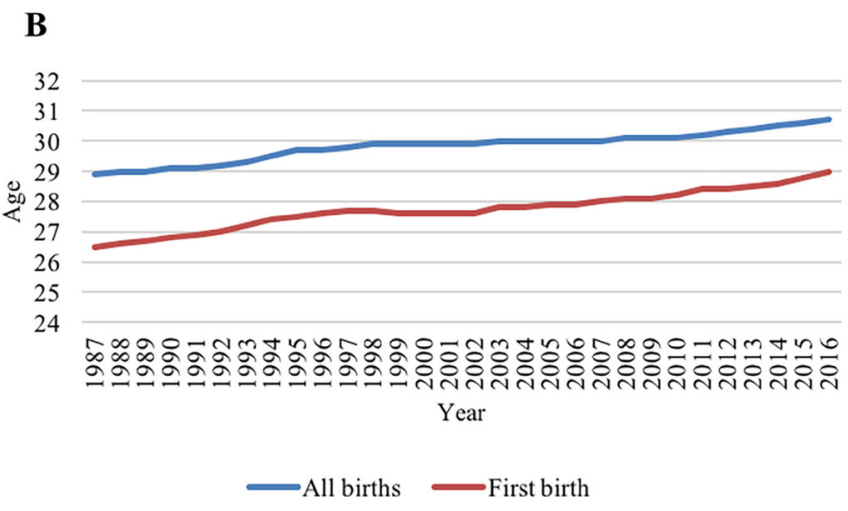

Figure 1 (A) The total fertility rate and crude birth rate, from 1900 to 2017 in Finland. (B) The mean maternal age at birth and mean maternal age at first birth, from 1987 to 2016 in Finland. Note: below-replacement fertility: the total fertility rate lower than 2.1 children per women.

$2017,{ }^{14}$ but only a few researchers have addressed the issue. Thus, this paper aims to describe temporal changes of total fertility rates and age-specific fertility rates in Finland over a 30-year period and to dissect the factors associated with the decline in fertility rates, including increased age at the first birth, the elevated proportion of childlessness and maternal education.

\section{METHODS}

Finland is a country of 5.5 million inhabitants in Northern Europe. The study population for this data encompasses all live births from 1987 to 2016, including information on 1792792 live births. The data for this study were obtained from the Medical Birth Register (MBR) which has been a comprehensive system for collecting birth data since 1987 . The MBR, maintained by the National Institute for Health and Welfare, covers more than $99.9 \%$ of births in Finland and includes individual-level demographic and health data of mothers. ${ }^{15}$ The MBR data were complemented with population-level information on childlessness, gathered from Statistics Finland to assess changes in fertility rates. Individual-level register data cannot be publicly available because of data protection laws and the sensitive nature of the data. The data on variables in registers are complete, and their content is in accordance with reality. ${ }^{16}$ Moreover, the quality of the register data has been constantly improved due to active use of data in research and decision-making. ${ }^{17}$ Thus, we believe that the data of registers are valid and reliable.

We used general measures of fertility, including total fertility rate and age-specific fertility rate to measure fertility at the population level. ${ }^{18}$ We provided the information on the total fertility rate and maternal age as the background information. We calculated age-specific fertility rate by maternal age at first birth, age-specific fertility by maternal age at first birth across educational groups and the effect of postponement and childlessness on total fertility rates by use of register-based data.

The crude birth rate is the total number of live births accruing in a population. The total fertility rate is the number of live births born to a hypothetical cohort of 1000 women, assuming that their mortality rate, before the end of reproduction, is zero. On the contrary of the crude birth rate, the denominator of the total fertility rate is women over their childbearing years. Therefore, the age distribution of the population has no confounding effect on fertility rate. The total fertility rate was considered to be above replacement level, if a fertility rate was at least 2.1 children per woman. The age-specific fertility rate is the ratio between the number of live births by women in a certain age group and the number of women in that age group in the given year which is standardised to the constant effect of age. Maternal age for the age-specific fertility rate was categorised as below 20 years, 20-24 years, 25-29 years, 30-34 years, 35-39 years, 40-44 years and 45 years or more. Sum of age-specific fertility rates for each cohort (1987-1991, 1992-1996, 1997-2001, 2002-2006, 2007-2011 and 2012-2016) was calculated as the completed fertility rate (the number of live births per women as 31 December 2016).

Data on childlessness have been available since 1989 . We focused on the childlessness of women at age 35, 40, 45 and 50 years, age of 50 was considered as the end of the reproductive age. We were unable to distinguish between voluntary and involuntary childlessness because the data were not originally gathered for the current research. Maternal education was categorised into four groups: basic education (9 years or less), upper secondary education (10-12 years), short cycle tertiary education (13-14 years) and university degree (15 years or more).

The effects of rising rates of childlessness and postponement of childbearing on the total fertility rates were modelled by a method previously described in the study of te Velde $e t a l .{ }^{19}$ The method was used to estimate the effects of postponement and childlessness on total fertility rates for the time periods of 1989 to 2016.

\section{Patient and public involvement}

Patients and the public were not involved in any aspect of this study. 


\section{RESULTS}

\section{Mean age of women}

In Finland, the mean age of women at birth increased from 28.9 to 30.7 years between 1987 and 2016. The increase was 2.5 years for first births, from 26.5 years in 1987 to 29.0 years in 2016 , with a steeper rise in the last 3 years (figure 1B). The observed increase in the mean maternal age indicated that postponement of childbirth continued in Finland.

\section{Total fertility rate}

Since 1987, the total fertility rate of Finnish women has fluctuated and approached the replacement level at two peaks in 1992 with 1.85 and in 2010 with 1.87 children per woman. After a period of stability in 2010, fertility rates have declined continuously and reached 1.57 children per woman in 2016 (figure 1A).

\section{Age-specific fertility rates}

After stratifying total fertility rates by the age group, it was illustrated that women aged 15-19, 20-24 years and 25-29 years in 1987, respectively, had more than 2.1, 1.5 and 1.2 times as many children in comparison with women in selected groups in 2016 (figure 2A). From 1987 to 2006, the fertility rate of women aged 25-29 years fluctuated at the highest level among all age groups and after that decreased to the lowest of all time in 2016. By considering the importance of postponing maternity, the fertility rate of women aged 30-34 years has been highest among all age groups since 2007. Moreover, the fertility rate of women aged 35-39 years surpassed the fertility rate of women aged 20-24 years in 2010.

Figure 2B depicts the completed fertility rate for two cohorts after five follow-up periods, assuming that women have completed their childbearing (see online supplementary figure 1). The completed fertility rate of women was negatively associated with the mean maternal age at first birth. Women who gave birth to their first child before the age of 30 years were able to maintain fertility rates above replacement level. As completed fertility rate of almost three live born was observed, when women had their first child under age of 21 years. The slight increase in the ultimate number of children at the end of childbearing ages is explained by use of medically assisted reproduction and a higher multiple pregnancy rate.

The relationship of completed fertility rate and the mean maternal age at first birth by educational levels is given in figure $2 \mathrm{C}$ and online supplementary figure 2 . As figure 2B,C illustrates, later childbearing was related to lower completed fertility rate, and similarly in each educational group. The differences in completed fertility rates, however, were relatively small across educational groups.

\section{Effect of rising childlessness rate and postponement of first birth on total fertility rates}

As a result of postponing childbearing to the end of reproductive ages, the proportion of childless women at age 50 has increased by $6 \%$ units, from 1989 to 2016 . In
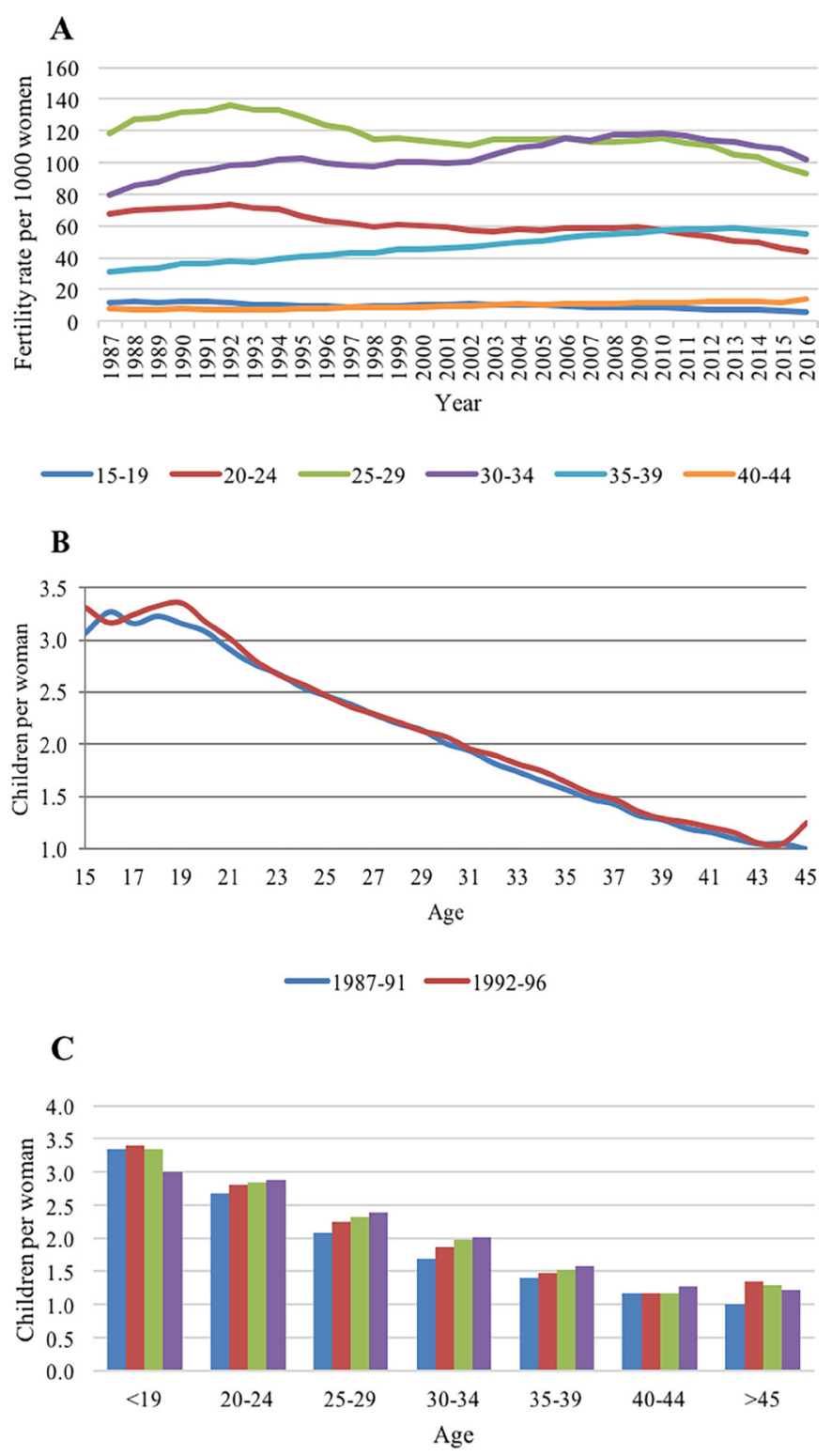

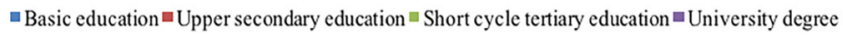

Figure 2 (A) Age-specific fertility rates, 1987-2016. (B) Completed fertility rate by age at first birth. (C) Completed fertility by age at first birth and educational level. Note: below-replacement fertility: the total fertility rate lower than 2.1 children per women.

$2016,19.6 \%$ of women remained childless at the age of 50 (figure $3 \mathrm{~A}$ ). The childlessness rate for women aged 35 years in the same period has grown by $9.5 \%$ units from $19.2 \%$ to $28.7 \%$. Furthermore, without delay since 1989 , the increase in total fertility rates mainly started after 1996. Delay of childbearing from 1989 reduced the total fertility rate by 0.05 to 0.12 children in the last 2 years (figure $3 \mathrm{~B}$ ) (see online supplementary table 1 ). For instance, the total fertility rate in 2016 (1.57) would have been between 1.62 and 1.69 children per woman, if the increase in the mean maternal age had stopped in 1989. 


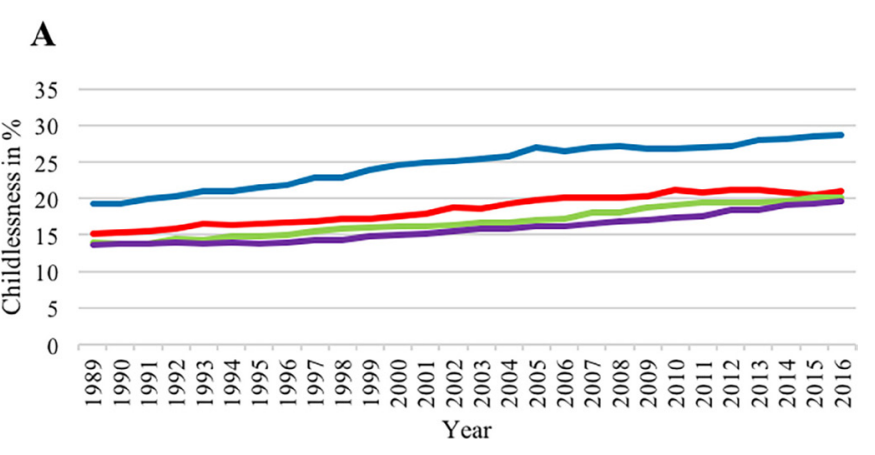

-Age 35 -Age $40-$ Age $45-$ Age 50

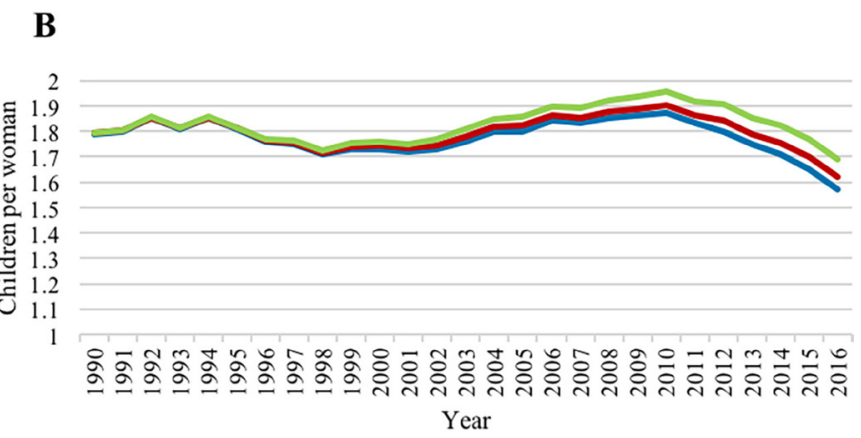

—TFR TFR lower limit $\longrightarrow$ TFR upper limit

Figure 3 (A) The proportion of childless women at the age of $35,40,45$ and 50 years, from 1989 to 2016 in Finland.

(B) The estimated effect of postponing pregnancy on total fertility rate without delay since 1989 in Finland. Note: belowreplacement fertility: the total fertility rate lower than 2.1 children per women. TFR, total fertility rate.

\section{DISCUSSION}

The results of the present study indicated that the total fertility rate of Finnish women has declined by 0.3 children from 2010 to 2016, and further to 1.49 in 2017, the lowest ever in Finland. ${ }^{14}$ The decline appeared to be associated with the increase in the mean maternal age at first birth by $9.4 \%$ and childlessness by $44.1 \%$. The completed fertility rate declined by age at first childbirth, similarly in all educational groups. Modelling the fertility trends suggested that if the rising level of childlessness and postponement had stopped in 1989, total fertility rates would have been higher between 1996 and 2016. Postponement of childbearing also changed the age distribution of births. Fertility rates of women aged 30 or more increased, but nulliparous women above the age of 30 years were not able to maintain the completed fertility rate at two children or more.

As proposed by Jensen $e t$ al, older women have been found to be able to sustain fertility rates above the replacement so that having a child between the age of 30 and 40 years is in biological limit. ${ }^{20}$ However, high fertility rates of women above 30 years of age were due to giving birth to several children which occurs rarely nowadays. This change in fertility pattern emanates from the decision of having lower number of children due to cultural, economic and social circumstances or results from childbearing postponement. ${ }^{21}{ }^{22}$ The present results suggested, that if maternal age at first births was 30 years or above, women had less time to give birth to two children, whereas in other cohorts later childbearing has not always been associated with fewer children (lower quantum).${ }^{23}$ Our findings are in line with previous studies that maternal age at first birth is interrelated with the ultimate number of children. ${ }^{24}{ }^{25}$ Sweden, Denmark and France were among the countries with the highest fertility rates in Europe, even though the mean maternal age at first birth in these countries was high. ${ }^{26}$ In the Finnish population, the increase in the mean maternal age at first birth has been gradual, but sufficient enough to decline fertility rates especially in recent years. If all women postpone childbearing to the later age, the effect of postponement on the total number of children will be significant. ${ }^{27}$ Because, not all women who postpone pregnancy will have a child mainly due to unstable partnership, expansion of education, participation in the workforce and the decline in fecundability with increasing female age. ${ }^{27} 28$

Previous studies on the association between women's educational level and completed fertility rate suggested that women with higher educational levels tend to have fewer children than women with short education. ${ }^{29-31}$ In the Nordic countries, the median maternal age at first birth has increased across all educational groups, with the largest postponement of first birth among highly educated women. ${ }^{23}$ The result of current study indicated that in Finland, as a welfare state with compatibility of employment and family formation, the negative impact of women's educational attainment on the total number of children was relatively weak. This may be also attributed to the fertility recuperation at higher ages among highly educated women in Finland. ${ }^{23} 32$

The current study is descriptive in nature and drawn from well-established population registers which have shown to have high coverage and validity. ${ }^{16}$ However, the results of this study need to be interpreted with caution, since the focus was on the total fertility rate by time and maternal age, without focus on specific exposure effect. Therefore, it was not possible to evaluate the causal effect of age or childlessness on fertility rates, and further studies are needed to dissect specific exposure effects rather than focusing on occurrence measures. In this study, we were unable to distinguish voluntary from involuntary childlessness.

Apart from the effect of postponement on fertility rates, the overall trend in fertility rates reflects complex changes we have faced within our modern industrialised societies. Some of these temporal changes are inevitable, but family-friendly policies may have the potential to compensate the negative impact of demographic changes on fertility rates. ${ }^{33}$ Although generous family policies have probably prevented Finland to be one of the countries with the lowest-low fertility with a total fertility rate below $1.3,{ }^{35}$ there may still be room for improvement. Awareness of family policies that encourage both fatherhood and 
motherhood at earlier ages, support young couples and influence spacing between first and second and higher order births, might increase fertility rates. Availability of medically assisted reproduction may also play a role since only half of the couples, who fail to conceive naturally, are seeking infertility advice or treatment, partly due to the limited infertility services. ${ }^{36}$ The role of medically assisted reproduction is known to be more important among older couples than other groups. ${ }^{97}$ Currently, around $5 \%$ of newborns are born after these treatments in Finland. ${ }^{38}$ There are, however, no information on the number of medically assisted reproduction users who do not get a child.

According to the studies of Virtala $e t$ al, the ideal family size among the majority of Finnish university students was two children, and only a minority expressed that they wanted no children. ${ }^{39} 40$ This discrepancy between the ideal family size and total/completed fertility rate further emphasises the importance of policies to help couples to reach their perceived ideal family size. The present study suggests that in this effort encouraging young motherhood is one of the key determinants to be improved.

\section{Acknowledgements We thank Professor Egbert te Velde for the constructive} feedback.

Contributors ZR did the literature search and drafted the manuscript, with critical input from SR, MG, SH. MG and SH designed the survey, with contributions and advice from SR. MG and ZR analysed the data and interpreted the results. All authors reviewed the manuscript. All authors have read and approved the final draft.

Funding The authors have not declared a specific grant for this research from any funding agency in the public, commercial or not-for-profit sectors.

Competing interests None declared.

Patient consent for publication Not required.

Ethics approval The ethical approval was gained from the National Institute of Health and Welfare (THL) (Permission number THL/876/5.05.00/2017) which is required by the national data protection legislation. For using publicly available data of Statistics Finland, permission was not required.

Provenance and peer review Not commissioned; externally peer reviewed.

Data sharing statement Due to national data protection rules, the register data cannot be shared. Researchers can apply similar data from the Medical Birth Register. No additional data are available.

Open access This is an open access article distributed in accordance with the Creative Commons Attribution Non Commercial (CC BY-NC 4.0) license, which permits others to distribute, remix, adapt, build upon this work non-commercially, and license their derivative works on different terms, provided the original work is properly cited, appropriate credit is given, any changes made indicated, and the use is non-commercial. See: http://creativecommons.org/licenses/by-nc/4.0/.

\section{REFERENCES}

1. Mills M, Rindfuss RR, McDonald P, et al. Why do people postpone parenthood? Reasons and social policy incentives. Hum Reprod Update 2011;17:848-60.

2. Keizer R, Dykstra PA, Jansen MD. Pathways into childlessness: evidence of gendered life course dynamics. J Biosoc Sci 2008;40:863-78.

3. Hammarberg K, Collins V, Holden C, et al. Men's knowledge, attitudes and behaviours relating to fertility. Hum Reprod Update 2017;23:458-80.

4. ESHRE Capri Workshop Group. Europe the continent with the lowest fertility. Hum Reprod Update 2010;16:590-602.
5. van Roode T, Sharples K, Dickson N, et al. Life-course relationship between socioeconomic circumstances and timing of first birth in a birth cohort. PLoS One 2017;12:e0170170.

6. Menken J, Trussell J, Larsen U. Age and infertility. Science 1986;233:1389-94

7. Larsen U, Yan S. The age pattern of fecundability: an analysis of French Canadian and Hutterite birth histories. Soc Biol 2000;47:34-50.

8. Schwartz D, Mayaux MJ. Female fecundity as a function of age: results of artificial insemination in 2193 nulliparous women with azoospermic husbands. Federation CECOS. N Engl J Med 1982;306:404-6.

9. American College of Obstetricians and Gynecologists Committee on Gynecologic PracticePractice Committee of the American Society for Reproductive Medicine. Female age-related fertility decline. Committee Opinion No. 589. Obstet Gynecol 2014;123:719-21.

10. Sartorius GA, Nieschlag E. Paternal age and reproduction. Hum Reprod Update 2010;16:65-79.

11. Steiner AZ, Jukic AM. Impact of female age and nulligravidity on fecundity in an older reproductive age cohort. Fertil Steril 2016;105:1584-8.

12. Toulemon L, Pailhé A, Rossier C. France: High and stable fertility. Demogr Res 2008;19:503-56.

13. Rothenbacher F. Finland. The European Population 1850-1945. The Societies of Europe. London: Palgrave Macmillan, 2002:199-229.

14. Statistics Finland. Total fertility rate at an all-time low. 2017 https:// www.stat.fi/til/synt/2017/synt_2017 2018-04-27 tie_001 en.htm (accessed 10 Apr 2018).

15. The National Institute for Health and Welfare (THL). Medical birth register. 2016 https://thl.fi/fi/web/thlfi-en/statistics/information-onstatistics/register-descriptions/newborns (accessed 10 Apr 2018).

16. Gissler M, Haukka J. Finnish health and social welfare registers in epidemiological research. Nors Epidemiologi 2004;14:113-20.

17. Gissler M, Mohangoo AD, Blondel B, et al. Perinatal health monitoring in Europe: results from the EURO-PERISTAT project. Inform Health Soc Care 2010;35:64-79.

18. Adams MM, Alexander GR, Kirkby RS, et al. Perinatal epidemiology for Public Health Practice. US: Springer, 2009:5-12.

19. te Velde $E$, Habbema $D$, Leridon $H$, et al. The effect of postponement of first motherhood on permanent involuntary childlessness and tota fertility rate in six European countries since the 1970s. Hum Reprod 2012;27:1179-83.

20. Blomberg Jensen M, Priskorn L, Jensen TK, et al. Temporal trends in fertility rates: a nationwide registry based study from 1901 to 2014 . PLoS One 2015;10:e0143722.

21. Frejka T, Sardon J-P. Cohort birth order, parity progression ratio and parity distribution trends in developed countries. Demogr Res 2007;16:315-74.

22. Zeman K, Beaujouan E, Brzozwsk Z, et al. Cohort fertility decline in low fertility countries: Decomposition using parity progression ratios. Demogr Res 2017;16:315-74.

23. Andersson G, Rønsen M, Knudsen LB, et al. Cohort fertility patterns in the nordic countries. Demogr Res 2009;20:313-52.

24. Morgan SP, Taylor MG. Low fertility at the turn of the twenty-first century. Annu Rev Sociol 2006;32:375-99.

25. Bongaarts J, Feeney G. On the quantum and tempo of fertility. Popul Dev Rev 1998;24:271-91.

26. Schmidt L, Sobotka T, Bentzen JG, et al. Demographic and medical consequences of the postponement of parenthood. Hum Reprod Update 2012;18:29-43.

27. Lutz W. Fertility rates and future population trends: will Europe's birth rate recover or continue to decline? Int J Androl 2006;29:25-33.

28. Berrington A. Childlessness in the UK. In: Kreyenfeld M, Konietzka D, Childlessness in Europe: Contexts, Causes, and Consequences: Springer, 2017:57-76.

29. Blossfeld H-P, Huinink J. Human capital investments or norms of role transition? how women's schooling and career affect the process of family formation. Am J Sociol 1991;97:143-68.

30. Liefbroer AC, Corijn M. Who, what, where, and when? Specifying the impact of educational attainment and labour force participation on family formation. Eur J Popul 1999;15:45-75.

31. Lappegård $T$, Rønsen $M$. The multifaceted impact of education on entry into motherhood. European Journal of Population / Revue européenne de Démographie 2005;21:31-49.

32. d'Albis H, Greulich A, Ponthière G. Education, labour, and the demographic consequences of birth postponement in Europe. Demogr Res 2017;36:691-728.

33. Lee S, Duvander AZ, Zarit SH. How can family policies reconcile fertility and women's employment? Comparisons between South Korea and Sweden. Asian J Women Stud 2016;22:269-88. 
34. Gauthier AH. The impact of family policies on fertility in industrialized countries: a review of the literature. Popul Res Policy Rev 2007;26:323-46.

35. Erlandsson A. Child home care allowance and the transition to second- and third-order births in Finland. Popul Res Policy Rev 2017;36:607-30.

36. Boivin J, Bunting L, Collins JA, et al. International estimates of infertility prevalence and treatment-seeking: potential need and demand for infertility medical care. Hum Reprod 2007;22:1506-12.

37. Kocourkova J, Burcin B, Kucera T. Demographic relevancy of increased use of assisted reproduction in European countries. Reprod Health 2014;11:37.
38. The National Institute for Health and Welfare (THL). Assisted fertility treatments 2016-2017. 2018 https://thl.fi/en/web/thlfi-en/statistics/ statistics-by-topic/sexual-and-reproductive-health/assisted-fertilitytreatments (accessed 30 May 2018).

39. Virtala A, Kunttu K, Huttunen T, et al. Childbearing and the desire to have children among university students in Finland. Acta Obstet Gynecol Scand 2006;85:312-6.

40. Virtala A, Vilska S, Huttunen T, et al. Childbearing, the desire to have children, and awareness about the impact of age on female fertility among Finnish university students. Eur J Contracept Reprod Health Care 2011;16:108-15. 